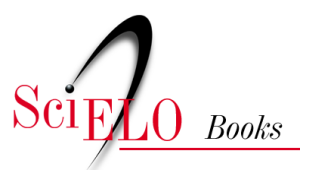

\title{
A produção do espaço urbano e o Programa Minha Casa Minha Vida em Russas - Ceará
}

\author{
Jéssica Liana de Sousa
}

\section{SciELO Books / SciELO Livros / SciELO Libros}

SOUSA, J. L. A produção do espaço urbano e o Programa Minha Casa Minha Vida em Russas - Ceará. In.: MAIA, D. S., and MARAFON, G. J., eds. O programa Minha Casa Minha Vida: habitação e produção do espaço urbano em diferentes escalas e perspectivas [online]. Rio de Janeiro: EDUERJ, 2020, pp. 245-268. ISBN: 978-65-00-03029-7. https://doi.org/10.7476/9786500030297.0010.

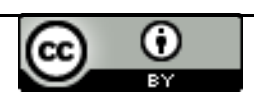

All the contents of this work, except where otherwise noted, is licensed under a Creative Commons Attribution 4.0 International license.

Todo o conteúdo deste trabalho, exceto quando houver ressalva, é publicado sob a licença Creative Commons Atribição 4.0.

Todo el contenido de esta obra, excepto donde se indique lo contrario, está bajo licencia de la licencia Creative Commons Reconocimento 4.0. 


\section{A produção do espaço urbano e o Programa Minha Casa Minha Vida em Russas - Ceará}

Jéssica Liana de Sousal

\section{Introdução}

A pesquisa dissertativa, ${ }^{2}$ da qual deriva este artigo, teve por objeto espacial a cidade de Russas, localizada no baixo Jaguaribe, Ceará, no Nordeste brasileiro. Este núcleo urbano possui 76.884 habitantes (IBGE, 2018), podendo ser considerada uma pequena cidade. Desta forma, aqui há que se considerar a dinâmica socioespacial de um núcleo urbano no interior do território do Nordeste brasileiro com as suas particularidades e singularidades, náo se esquecendo do contexto global.

${ }^{1}$ Graduada em Licenciatura em Geografia pela Faculdade de Filosofia Dom Aureliano Matos (UECE/FAFIDAM) e mestre em Geografia pela Universidade Federal da Paraíba.

2 Este texto provém da pesquisa desenvolvida em nível de mestrado no Programa de Pós-Graduação em Geografia da Universidade Federal da Paraíba (UFPB), no período de março de 2016 a agosto de 2018, sob a orientaçáo da Profa. Dra ${ }^{a}$. Doralice Sátyro Maia e financiada pela Coordenação de Aperfeiçoamento de Pessoal de Nível Superior (CAPES). 
Mapa 1 - Localização do município de Russas - Ceará
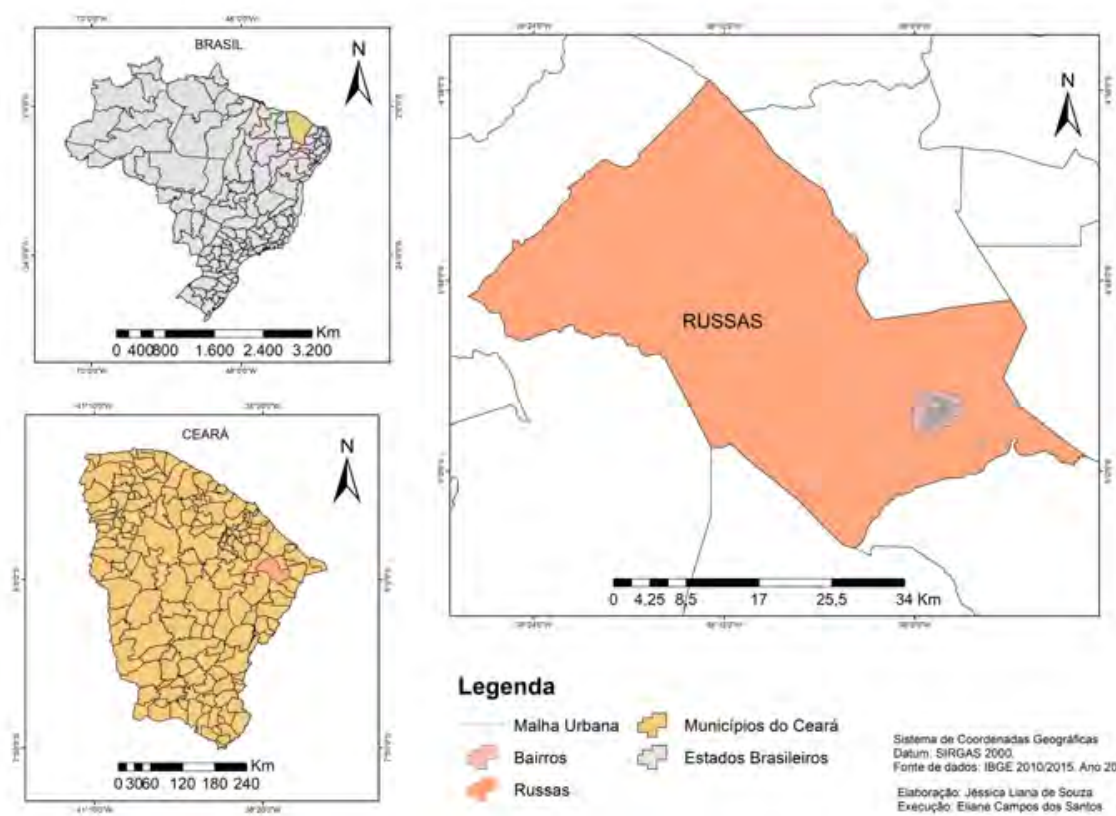

Sistema de Coordenadas Geogratcas
Datum. SRRGAS 2000 . Forte de dados: IBGE 20102015. Ano 2016

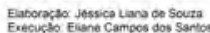

Fonte: IBGE 2010/2015. Ano 2018.

A institucionalização do Programa Minha Casa Minha Vida no Brasil no ano de 2009 dá-se como medida econômica anticíclica, ${ }^{3}$ visando também promover a produçáo de habitaçóes para a população de faixas de renda média à baixa, tem-se a expansão dos investimentos imobiliários em todo o país com associação entre capital imobiliário e capital financeiro. Observamos, neste momento, que náo somente os espaços metropolitanos, mas as cidades de menor porte, passam a atrair cada vez mais investimentos do tipo. Em 2009, a cidade de Russas passa a aderir ao PMCMV, ação motivada pelo interesse das construtoras que procuraram a Caixa Econômica Federal (CEF) para realizar os financiamentos dos primeiros empreendimentos construídos na faixa $2 \mathrm{e}$, posteriormente, na faixa 3 do respectivo programa. ${ }^{4}$

${ }^{3}$ Em decorrência da crise do capital, cujo ápice é demarcado no ano de 2008.

${ }^{4}$ Como mencionado em outros capítulos deste livro, o PMCMV nas suas três versóes sofreu alteraçóes. No início, eram três faixas; na última versão, a de 2017, foi criada uma faixa intermediária, a Faixa 1,5 . Nesta faixa, o limite de renda mensal era até $\mathrm{R} \$$ 2,6 mil; na Faixa 2, limite de renda mensal até R $\$ 4$ mil; e, na Faixa 3, limite de renda 
Tal política habitacional apresenta expressivos desdobramentos na produção e reproduçáo do espaço urbano da cidade estudada, alterando significativamente sua estrutura e dinâmica urbana. Esse processo foi constatado em várias realidades brasileiras - a exemplo de estudos como Araújo (2017) em Cajazeiras - PB ; Valença (2018) em Caruaru - PE; Volochko (2007) em Sáo Paulo - SP; e Pequeno (2013) em Fortaleza - CE, dentre outros realizados em várias cidades brasileiras. Em Russas a implantação desse programa em território nacional incrementou o mercado imobiliário que, por sua vez, promoveu diversas transformaçóes socioespaciais. Assim, pensar e compreender a atuaçáo do PMCMV em uma cidade do interior do Nordeste contribui para uma avaliaçáo mais precisa e ampliada das repercussóes desta política governamental, e melhor entendimento do processo de (re)produção e o de expansão urbana.

O principal objetivo aqui é apresentar a cidade de Russas com a finalidade de mostrar quais foram as repercussóes do Programa Minha Casa minha Vida (PMCMV) na (re)produçáo do espaço da referida cidade e os empreendimentos construídos, especialmente os inseridos na faixa 2, visto que é a faixa predominante na cidade.

Como caminho metodológico, utilizamo-nos de pesquisa bibliográfica, de pesquisa documental com a obtenção de dados estatísticos e de informaçôes e de material cartográfico. As informaçôes e os dados foram obtidos em órgãos públicos como a Prefeitura Municipal de Russas e a Secretaria de Desenvolvimento Econômico e Tributos, além dos sites de instituiçóes - Instituto Brasileiro de Geografia e Estatística (IBGE), Instituto de Pesquisa e Estratégia Econômica do Ceará (IPECE) e a Fundação João Pinheiro (FJP) - e das construtoras e incorporadoras imobiliárias. Acrescenta-se como procedimento metodológico a realização do trabalho de campo quando se concretizou o exercício da observação para melhor caracterizaçáo dos empreendimentos.

O texto está estruturado com essa introdução e dois subtítulos: "A produção do espaço em Russas e a política habitacional com o PMCMV" e "A produção da habitação pelo PMCMV". Para encerrar, teceremos algumas consideraçóes finais.

mensal até R\$ 9 mil. Nas primeiras versóes do Programa, as rendas familiares correspondentes a cada faixa era definida pelo número de salários mínimos. 


\section{A produção do espaço em Russas e a política habitacional com o PMCMV}

Segundo o último estudo elaborado pelo IBGE (2017) sobre a classificação e caracterização dos espaços rurais e urbanos do Brasil, o Município de Russas se classifica como predominantemente urbano, ${ }^{5}$ ou seja, apresenta maior concentração da população em área urbana, embora, de acordo com Elias (2013), a sua economia seja dinamizada pelo agronegócio e atividades tipicamente rurais. Além disso, a cidade de Russas apresenta uma centralidade na região na qual se insere - principalmente pelos serviços de educação e atividades comerciais -, apesar do seu relativo baixo contingente populacional, considerando o quadro demográfico urbano brasileiro.

Como se pode observar no quadro 1 , foi justamente a partir da década de 1990 que a população urbana do Município de Russas ultrapassou sua população rural. A migração campo-cidade nesse período foi estimulada pela decadência das atividades no campo, destacadamente o algodáo e a cera da carnaúba.

\begin{tabular}{l|l|l|l|l|l|l}
\multicolumn{6}{c}{ Quadro $1-$ Evolução da população Urbana e Rural em Russas até o ano de 2016} \\
\hline & 1970 & 1980 & 1991 & 2000 & 2010 & 2016 \\
\hline Total & 34.239 & 38.513 & 46.566 & 57.320 & 69.833 & 75.762 \\
\hline Urbana & 11.374 & 18.558 & 27.055 & 35.323 & 44.952 & 48.768 \\
\hline Rural & 22.865 & 19.955 & 19.511 & 21.997 & 24.881 & 26.994 \\
\hline
\end{tabular}

Fonte: Dados retirados do IPECE/2017. Elaborado pela autora.

Destarte, com base nas informaçóes disponibilizadas, podemos verificar que, no período de 1990 a 2016, houve um crescimento exponencial da população total e urbana do município. Como justificativa para tal elevação, destacamos a implantação da indústria calçadista Dakota no final dos anos 1990 e do campus da Universidade Federal do Ceará (UFC) em 2014, em função da política de interiorização e expansão das instituiçôes de ensino superior (IES). Também deve-se ressaltar os investimentos feitos e produzidos por setores e agentes do mercado imobiliário e da construçáo civil na produção habitacional a partir do PMCMV e, por fim, a presença do agronegócio

5 Contudo, de acordo com Elias (2013), trata-se de uma cidade com economia dinamizada pelo agronegócio e com atividades tipicamente rurais em partes do seu território. 
como a principal atividade econômica na região. Ou seja, esses fatores foram e são determinantes para impulsionar o crescimento demográfico e a expansão do tecido urbano de Russas.

Da década de 1990 em diante, a população rural também apresentou significativo crescimento, muito embora seja bastante inferior se comparado ao da população urbana. Certamente um dos fatores que justificaram esse aspecto foram as políticas de modernização das atividades agrícolas (agronegócio) presentes na Região do Baixo Jaguaribe. Em Russas, tais políticas se materializam por meio do Perímetro Irrigado Tabuleiro de Russas (PITR). ${ }^{6}$

Como já se sabe, o crescimento populacional é um dos fatores que condicionam o processo de urbanização. Em Russas, a partir do final dos anos de 1990, tal incremento tem se dado pela dinâmica comercial, dos serviços e das atividades agroindustriais.

As primeiras fábricas instaladas no munícipio localizaram-se no centro da cidade e foram fundamentais para a instalação de alguns serviços, como a energia elétrica e a iluminação pública. Na segunda metade do século XX, duas novas indústrias se instalaram na cidade: a RICASA (Russas Indústria Comércio e Agricultura S/A), em 1966, localizada na Avenida Dom Lino, principal via de circulação da cidade; e a RICOL (Russas Indústria e Comércio de Óleos Ltda), em 1973, que teve sua planta instalada na Rua João Marcial Pereira, atualmente bairro Nossa Senhora de Fátima.

Em 1998, como já mencionado, foi implantada a fábrica de calçados Dakota Nordeste S/A. O bairro Tabuleiro do Catavento foi escolhido pela Prefeitura Municipal como lugar para a sua localização. Inicialmente em um galpão situado no Bairro Alto São João, dois anos depois passou para seu atual endereço, na Avenida Coronel Antônio Cordeiro, às margens da BR116, no bairro Tabuleiro do Catavento. O terreno foi cedido pela Prefeitura Municipal para a relocação da Dakota-Russas e é conexo aos terrenos doados para a construção dos Conjuntos Habitacionais Padre Abdon Valério e Dr.

${ }^{6}$ Localiza-se nos municípios de Russas, Limoeiro do Norte e Morada Nova, mais precisamente no baixo Vale do Jaguaribe, na chamada zona de Transição Norte dos Tabuleiros de Russas. A área é constituída por uma faixa contínua de terras agricultáveis ao longo da margem esquerda do Rio Jaguaribe, entre a cidade de Russas e a confluência do rio Banabuiú, região nordeste do Estado do Ceará. É administrado pelo Departamento Nacional de Obras contra a Seca (DNOCS). 
José Martins Santiago. O Cartograma 1 foi construído em 2002 e o segundo, em 2003 , logo após a instalação da fábrica de calçados no seu novo endereço.

Cartograma 1 - Localização dos conjuntos Padre Abdon Valério e Dr. José Martins Santiago

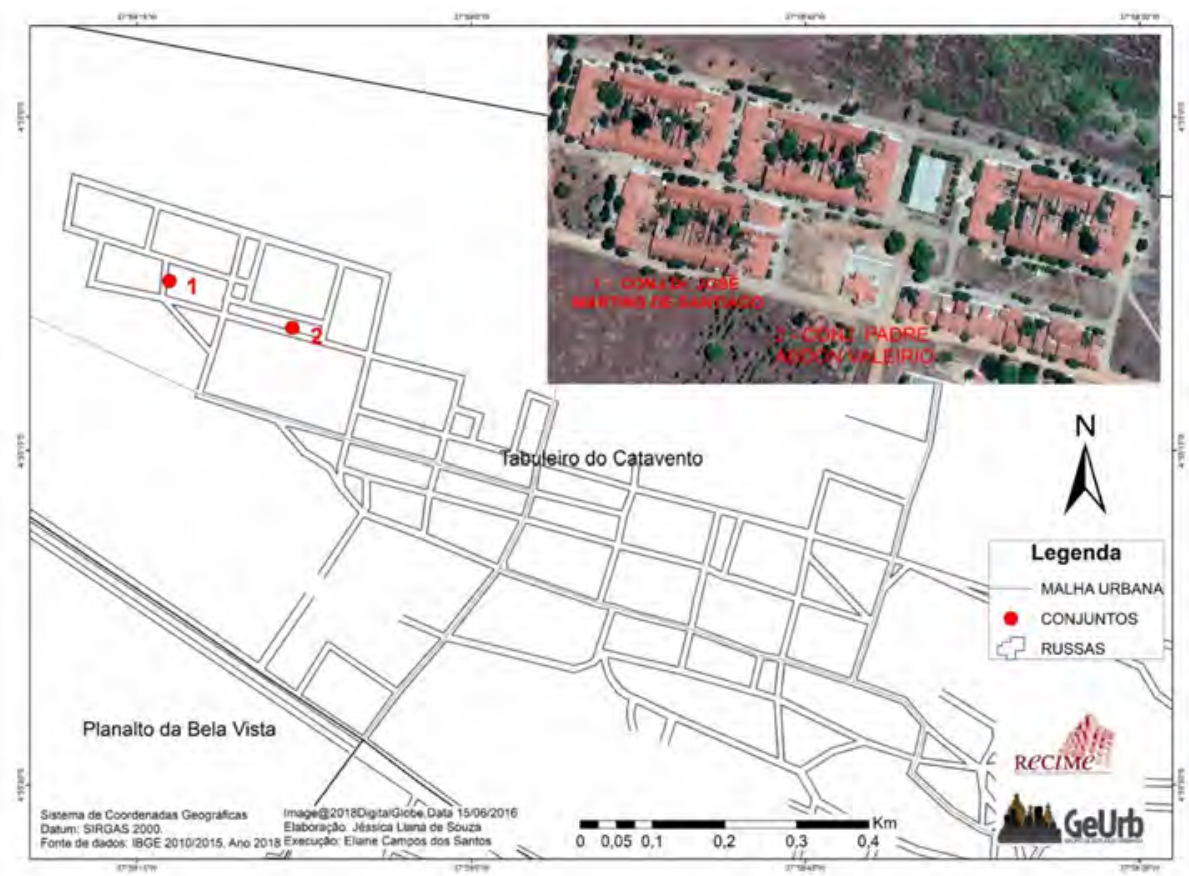

Fonte: IBGE 2010/2015. Ano 2018.

A instalação do Campus Avançado da UFC (figura 1) em Russas expressa o entendimento de como essas instituiçóes públicas repercutem na dinâmica das cidades, na ação dos agentes produtores do espaço e na reconfiguração do espaço intraurbano. Embora suas atividades só tenham iniciado em 2014, desde que a instalação do campus foi confirmada, passou-se a noticiar grandes expectativas quanto a uma nova dinâmica que ele provocaria na cidade. Para o setor imobiliário, significou um fator essencial na ampliação e reprodução habitacional na cidade, tomando-o como símbolo de futuro promissor da cidade e utilizando como marketing em seus negócios, além de gerar aumento exponencial nos preços dos terrenos e dos aluguéis, principalmente nas proximidades do campus. 
Figura 1 - Obras de expansão no campus universitário - UFC/Russas

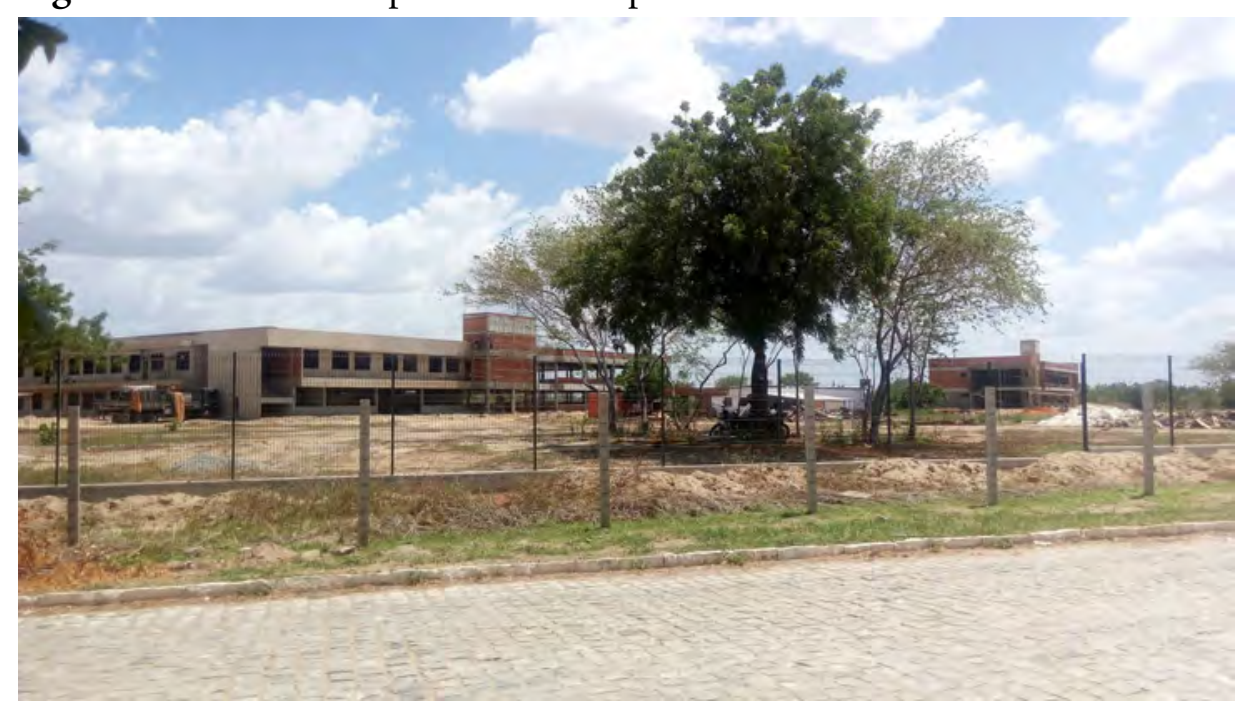

Fonte: Acervo próprio (Sousa, 2018. Trabalho de Campo - mar. 2018.

No que se refere à legislação e à política urbana, o município de Russas teve seu primeiro Plano Diretor elaborado em 1981 pelo Governo do Estado do Ceará, por meio do Departamento de Desenvolvimento Microregional. Em 2017, tiveram início as primeiras discussóes e audiências públicas para a revisão do Plano Diretor Participativo que teve vigência nos anos de 200708. Dentre as diretrizes e as estratégias delineadas na revisão do Plano Diretor Municipal, destaca-se a ampliação e melhoria do atendimento de saneamento básico, especialmente do esgotamento sanitário e a integração da política habitacional às demais políticas públicas, priorizando o atendimento das necessidades habitacionais de interesse social.

Além dessas diretrizes gerais, o plano especifica a criação de um sistema municipal de habitação de interesse social, a atualização do Plano Local de Habitação e Interesse Social (PLHIS), a elaboração de normas e instrumentos legais que favoreçam a habitação de interesse social e o apoio às açóes do PMCMV para atender as famílias de baixa renda. No entanto, é importante afirmar que, apesar do PLHIS ter realizado o levantamento das demandas habitacionais, sobretudo para habitação de interesse social (com o PMCMV em vigor), até o ano de 2017 ainda não tinha sido efetuada nenhuma ação no município referente à habitação social desde sua criação. Essa realidade só 
começou a se modificar recentemente, em 2018, com a construção (ainda em andamento) do primeiro projeto do PMCMV faixa 1.

Dessa forma, afirma-se que as primeiras práticas de intervenção estatal na produção habitacional de Russas se deram a partir da década de 1980 no contexto de criação da principal política habitacional no Brasil durante o período do Banco Nacional de Habitaçáo (BNH). Posteriormente, como exposto, a implantaçáo da indústria Dakota no final dos anos de 1990 provocou inicialmente um atrativo para a produção de habitaçóes no seu entorno, mas de forma inexpressiva.

Observamos que foi a partir do PMCMV que efetivamente a produção habitacional em Russas se consolidou e o mercado imobiliário local se expandiu. Ademais, foi mediante o PMCMV, em 2009, que o Estado passou a atuar de forma incisiva nesta cidade, onde se percebe facilmente a elevada produção de empreendimentos em comparação aos anos anteriores.

Pelo exposto, podemos perceber uma íntima relação entre as açóes do Estado e as estratégias do setor imobiliário, principalmente para fins especulativos e com elevada extração de renda. $\mathrm{O}$ empreendimento mais representativo dessa expansão do mercado imobiliário sob a instalação do Campus Universitário na cidade é o Condomínio Residencial Santiago I e II, construídos pelo PMCMV (faixa 3) localizados na maior área de crescimento e valorização imobiliária da cidade. Entendemos que se confirma, de fato, a tese de que cada vez mais a expansão e interiorizaçáo das IES repercutem concretamente na produção de novas relaçóes e dinâmicas nos espaços urbanos, dado o papel desempenhado pelas universidades como agentes da reestruturação urbana. Tal afirmativa corrobora o que escreve Henrique (2015):

A compreensão do papel das universidades como agentes da (re)estruturação urbana e das cidades torna-se importante, tanto em razão do volume de recursos financeiros movimentados quanto pela modificação de dinâmicas intraurbanas (moradia, circulaçáo, usos, etc.) e do cotidiano dos moradores. (p. 1).

Reafirma-se que, nos últimos dez anos, o setor imobiliário se expandiu de maneira significativa em Russas, inicialmente por meio de loteamentos regularizados e pelo crescimento do mercado de venda e locaçáo de prédios comerciais e residenciais, principalmente no centro da cidade. No entanto, de forma mais expressiva, há pelo menos cinco anos esse setor passa por uma 
reestruturação mais significativa e dinâmica que a demonstrada anteriormente. Compreendemos que esse novo "período" do mercado imobiliário em Russas pode ser caracterizado pelos seguintes elementos: lançamentos de loteamentos planejados e fechados, dotados de infraestruturas, como pavimentação, água e energia elétrica; abertura de novos escritórios imobiliários; surgimento de empresas especializadas na construção civil; crescimento da comercialização de novas residências e apartamentos; e construção de condomínios verticais e horizontais fechados. Destaca-se que os três últimos elementos demonstram ser dinamizados pelo crescimento e maior acesso aos financiamentos e subsídios habitacionais ofertados pelo PMCMV.

Dessa forma, podemos afirmar que a expansão urbana se dá reproduzindo o "formato" centro - periferia decorrente da conjunção de processos: do contínuo crescimento populacional, modernização das indústrias ceramistas, ações do Estado por meio de obras de infraestrutura, construçáo de conjuntos habitacionais e instalação de órgãos públicos e, mais recentemente, da chegada da indústria calçadista e, ainda, a atuação dos proprietários fundiários e dos promotores imobiliários a partir do PMCMV.

Contudo, para além desses processos que induzem a expansáo urbana, vale destacar a ausência de uma política urbana municipal eficaz, inclusive no que diz respeito à atualização da legislação urbana como também a demanda por habitaçôes pela população de baixa renda. Esta última é uma das problemáticas que vem se agravando ao longo do tempo, recebendo intervençóes pontuais em alguns períodos, contudo, permanecendo sem a resolução definitiva. Assim, indica-se uma suposta contradição: o crescimento da indústria da construção civil, a edificação de um número expressivo de habitações no âmbito da Política Nacional do Programa Minha Casa Minha Vida e o crescimento da demanda habitacional. Tal incoerência já foi constatada por vários pesquisadores que vêm se dedicando à análise do PMCMV, cujas críticas são expressas especialmente no que se refere à linha de atendimento ao mercado imobiliário, mas que também se revelam na cidade de Russas, mesmo esta náo se configurando um centro urbano de maior centralidade na rede urbana ou de uma dinâmica urbana táo expressiva como as cidades que se situam em níveis superiores da hierarquia urbana. Tal fato reforça a importância da análise realizada e ora apresentada.

Torna-se perceptível um crescimento da malha urbana e a formação de uma periferia na cidade de Russas são processos decorrentes do contínuo 
crescimento populacional, da modernização das indústrias ceramistas, das ações do Estado por meio de obras de infraestrutura, construção de conjuntos habitacionais e instalação de órgãos públicos, e, mais recentemente, da chegada da indústria calçadista e da atuação dos proprietários fundiários e dos promotores imobiliários a partir do PMCMV.

\section{O Programa Minha Casa Minha Vida em Russas}

Para melhor entendermos as repercussóes do PMCMV em Russas vale trazer algumas informaçóes sobre o déficit habitacional. Segundo os dados elaborados pela Fundação João Pinheiro a partir do Censo Demográfico de 2010, o DH total de Russas era de 1.834 unidades habitacionais. A tabela 1 mostra os dados referentes ao $\mathrm{DH}$ em Russas decomposto em variáveis pelo tipo de habitação.

Tabela 1 - Déficit habitacional total e relativo, por componente, no Estado do Ceará e no Município de Russas - 2010

\begin{tabular}{c|c|c|c|c|c|c|c|c|c|c}
\hline & \multicolumn{2}{|c|}{$\begin{array}{c}\text { Déficit Habita- } \\
\text { cional }\end{array}$} & \multicolumn{2}{c|}{$\begin{array}{c}\text { Domicílios } \\
\text { precários }\end{array}$} & \multicolumn{2}{c|}{$\begin{array}{c}\text { Coabitaçáo } \\
\text { familiar }\end{array}$} & \multicolumn{2}{c|}{$\begin{array}{c}\text { Ônus excessivo } \\
\text { com aluguel }\end{array}$} & \multicolumn{2}{c}{$\begin{array}{c}\text { Adensamento } \\
\text { em domicílio } \\
\text { alugado }\end{array}$} \\
\cline { 2 - 11 } & Total & Relativo & Total & Relativo & Total & Relativo & Total & Relativo & Total & Relativo \\
\hline Ceará & 276.284 & 11,66 & 46.028 & 1.94 & 125.745 & 5.31 & 79.478 & 3.35 & 25.033 & 1.06 \\
\hline Russas & 1.834 & 8,99 & 269 & 1,32 & 1007 & 5,94 & 471 & 2.30 & 87 & 0,43 \\
\hline
\end{tabular}

Fonte: Fundação João Pinheiro (2010). Elaboração própria.

Pelos números apresentados na tabela 1 , verifica-se que no estado do Ceará e no município de Russas o maior responsável pelo déficit habitacional é a população em condição de coabitação familiar, e a segunda condição é o número de habitantes que apresentam ônus excessivo com aluguel. Importante mencionar que o número total de domicílios particulares permanentes em Russas é de 20.411. A Fundação João Pinheiro (2010) mostra que "embora o ônus com aluguel seja um componente mais expressivo nas áreas metropolitanas (35,8\% do déficit), é forte também nas áreas não metropolitanas $(25,6 \%)$ ". No caso de Russas, percebemos que isso ocorre porque o aluguel tem sido a solução mais frequente para aqueles que não possuem casa própria. A grande parte do déficit urbano se concentra na população cuja renda 
é de até três salários mínimos e que, portanto, tem dificuldades em arcar com o pagamento de aluguéis. Assim, o incremento de unidades habitacionais financiadas pelo PMCMV - como são todos até o ano de 2017 - nas faixas 2 e 3 não atende ao déficit habitacional.

Tal fato merece ainda ser melhor analisado, uma vez que, no ano de 2019, o PMCMV sofreu cortes de orçamento e os ajustes feitos dirimem mais o fomento e os subsídios para os financiamentos para a população mais pobre, a saber, a faixa 1 em que o déficit habitacional é preponderante. Ou seja, a redução de investimentos nesta faixa impacta severamente a aquisição de moradias para a classe trabalhadora. Reafirma-se que até 2017 não existiam empreendimentos direcionados à faixa 1 em Russas. Concomitantemente, os recursos aplicados nas faixas correspondentes a atuação do mercado imobiliário (faixas 2 e 3) foram mantidas e até expandidas. Tal acréscimo deve-se ao expressivo aumento de investimentos para o setor privado na produção habitacional e às alteraçóes nos valores das faixas de renda e do teto dos preços de imóveis requeridas por setores do mercado imobiliário. No quadro 2 temos a distribuição e a quantidade de empreendimentos produzidos em Russas no período de 2009 a 2018.

Quadro 2 - Empreendimentos do PMCMV em Russas no período de 2009 a 2018

\begin{tabular}{l|l|l|l|c|c|c}
\hline Faixa & Modalidade & $\begin{array}{l}\text { Empreendi- } \\
\text { mento }\end{array}$ & Construtora & $\begin{array}{c}\text { No UH } \\
\text { Contratadas }\end{array}$ & $\begin{array}{c}\text { No UH } \\
\text { Concluídas }\end{array}$ & $\begin{array}{c}\text { No UH } \\
\text { Entregues }\end{array}$ \\
\hline $\mathbf{1}$ & Empresas & $\begin{array}{l}\text { Residencial } \\
\text { Tabuleiro do } \\
\text { Catavento }\end{array}$ & $\begin{array}{l}\text { CR DUAR- } \\
\text { TE ENGEN }\end{array}$ & 117 & - & - \\
\hline $\mathbf{2}$ & CCFGTS & & & 1.060 & 1.060 & 910 \\
\hline $\mathbf{3}$ & CCFGTS & & & 56 & 56 & 46 \\
\hline Total & & & & 1.233 & 1.116 & 956 \\
\hline
\end{tabular}

Fonte: Dados coletados no Ministério das Cidades (2018). Posição: 30 jun. 2018. Elaboração própria.

Sabe-se que os empreendimentos comercializados pelo programa podem ser unifamiliares e multifamiliares, estando ou não inseridos em condomínios ou organizados em agrupamentos de casas. Para cada uma dessas tipologias existem requisitos que devem ser cumpridos para que o projeto seja aprovado pela CEF para assim poder ser comercializado por meio do programa. 
Em Russas, ocorre a comercialização das duas tipologias: unifamiliares e multifamiliares. No entanto, há a predominância dos conjuntos de casas construídas de forma geminada e de arquitetura semelhante. Essa forma de construção é um mecanismo utilizado pelas empresas a fim de economizarem espaço, materiais, tempo de construção e trabalho, garantindo maior rentabilidade na produção desses empreendimentos.

Os primeiros contratos realizados pelo PMCMV em Russas foram efetivados ainda em 2009, construídos pela empresa ESBRA Construçáo Civil Ltda., que possui sede em Fortaleza. (quadro 2). O empreendimento não possui nome e constitui-se de blocos de dois pavimentos de apartamentos, computando um total de oito unidades domiciliares. Os apartamentos são organizados por blocos, cada um composto por oito apartamentos. Cada apartamento possui dois quartos, um banheiro, sala e cozinha americana. Eles são distribuídos em quatro tipos de plantas, com área total variando entre 47,69 $\mathrm{m}^{2}$ e 49,73 $\mathrm{m}^{2}$. (Figuras 2 e 3).

A partir de 2010, ou seja, após a institucionalização do PMCV, iniciou-se a construção de unidades familiares agrupadas, formando os primeiros conjuntos de casas construídas na cidade através do referido programa. Estas foram edificadas nos bairros Tabuleiro do Catavento, Vila Ramalho e Vila Matoso. Segundo as definiçóes do IBGE, a localização desse empreendimento se encontra fora dos limites desse bairro e até mesmo do perímetro urbano. (Figura 4). 
Figuras 2 e 3 - Primeiro empreendimento do PMCMV em Russas - Faixa 2
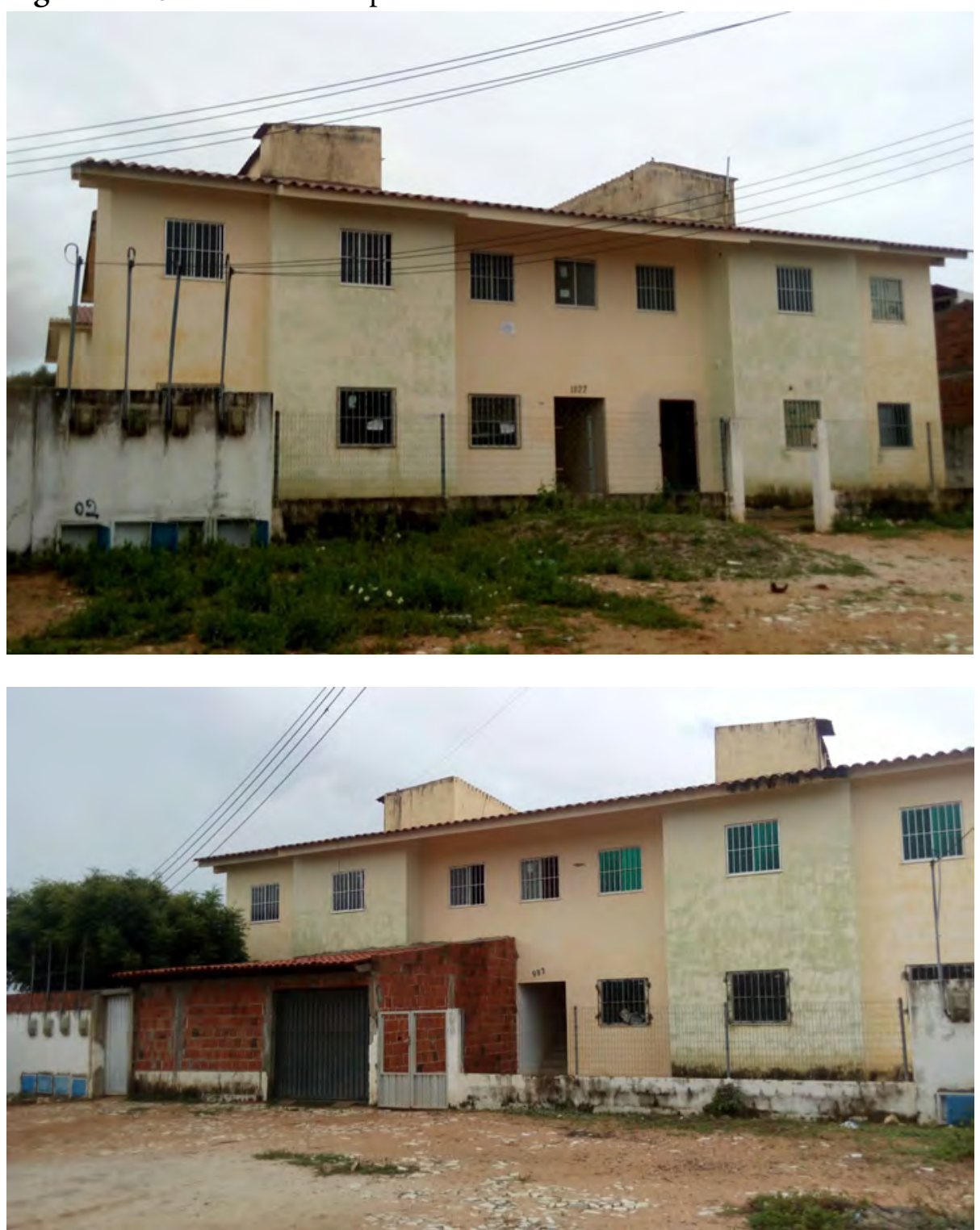

Foto: Sousa, 2018. Trabalho de Campo - mar. 2018.

Acrescenta-se que as primeiras empresas de construção civil surgem na cidade após 2009. Estas empresas são de capital local. Elas se consolidaram no mercado local e podem ser vistas como "especializadas" na construçáo de 
casas para serem vendidas por meio do PMCMV. Em entrevista com o proprietário da MS Construções e Incorporações, ele afirma que, “esse programa tem fortificado o mercado imobiliário local, mesmo nesse período de crise política e econômica e os investimentos para as faixas 2 e 3 foram mantidas, eles só reduziram a faixa 1". Aqui é possível observar os interesses reais do setor imobiliário e que foram os mais beneficiados por esse programa: as faixas de renda intermediária e elevada mantiveram os investimentos, enquanto a faixa destinada para habitação social (faixa 1), em que os subsídios são fundamentais para a compra e acesso à moradia, teve cortes significativos no orçamento. Tal fato revela o perfil mercadológico do programa, já que Russas, até meados de 2017, não possuía empreendimentos destinados à faixa 1 .

Em 2009 começaram a surgir as primeiras empresas locais do ramo da construção civil se tornando, "especializadas" na construção de empreendimentos com as características determinadas pelo PMCMV. Entre elas se destacam a MS Construçóes e incorporaçóes Ltda. e a S. Gurgel Empreendimentos Imobiliários Ltda. Atualmente essas duas empresas praticamente dominam o mercado de construção desses empreendimentos e administram também as vendas desses imóveis. Sendo que a MS Construçóes e Incorporaçóes é a que possui maior capital da cidade.

Figura 4 - Casas na Vila Ramalho - Faixa 2

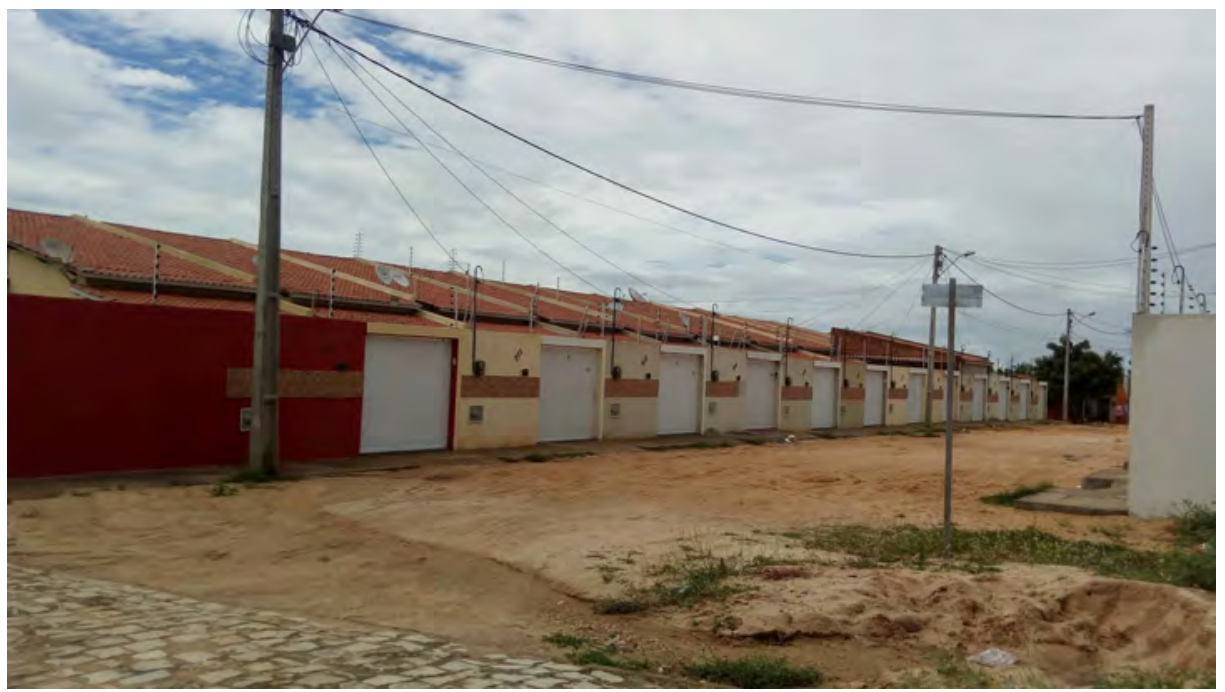

Foto: Sousa, 2018. Trabalho de Campo. 
Um dos exemplos de empreendimentos de domicílios unifamiliares da faixa 2 é o Loteamento Boa Vista, inaugurado em 2012 e construído pela empresa Tec Urbanismo. Ele teve início com a venda de lotes e, mais recentemente, em sua segunda etapa de expansão, a comercialização foi de casas já construídas. Este empreendimento localiza-se em área mais próxima ao centro da cidade e com a infraestrutura e vias de acesso. Além disso, a sua localização em frente à Lagoa da Caiçara é considerada pelo mercado imobiliário como a melhor área de localizaçáo e a de maior expansáo, juntamente com o bairro da Cidade Universitária. Por conseguinte, os preços dos imóveis são superiores a outros com tipologia similar, mas com localização menos atrativa. Os lotes residenciais possuem área média de $150 \mathrm{~m}^{2}$ e os comerciais de $300 \mathrm{~m}^{2}$. As casas são compostas por sala, dois quartos, dois banheiros, cozinha americana, garagem, quintal e churrasqueira e possuem $70 \mathrm{~m}^{2}$ de área construída . Os valores dessas casas são de $\mathrm{R} \$ 130.000 .00$, o valor máximo de acordo com o teto estabelecido pelo PMCMV em Russas com as modificações em 2017 (figura 5):

Figura 5 - Casas para vendas no Loteamento Bela Vista

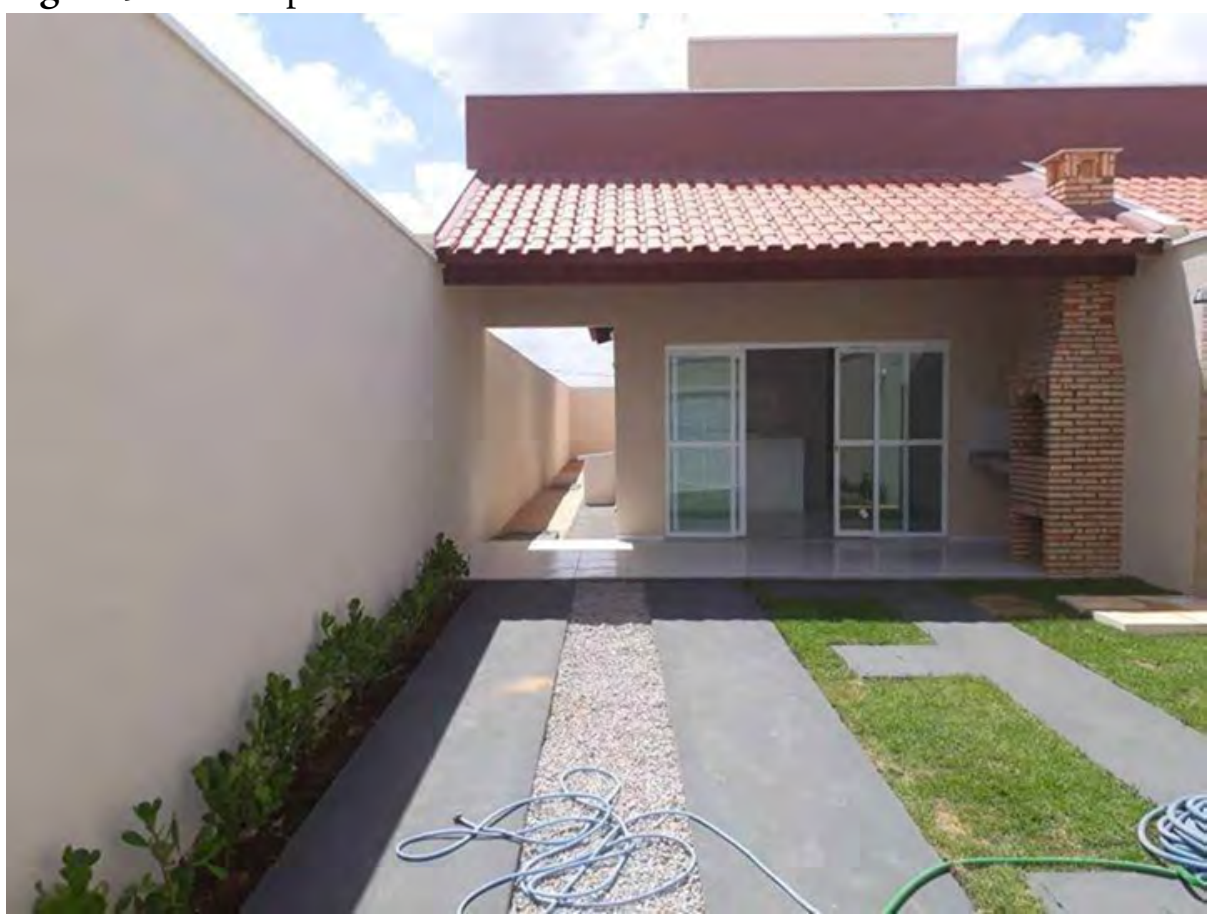

Foto: Sousa, 2018. Trabalho de Campo. 
As primeiras vendas das unidades do Condomínio Residencial Santiago I e II foram realizadas ainda na fase "da planta". Dentre os empreendimentos que a MS Construçôes e Incorporaçôes constrói na cidade tem-se o Residencial Unifamiliar. Este possui $83,89 \mathrm{~m}^{2}$ de área total construída em um terreno com área total de $180,55 \mathrm{~m}^{2}$. As casas possuem cozinha, varanda, sala de estar, dois quartos e uma suíte. Eles se inserem na faixa 2 do programa.

Dentre as empresas e escritórios de construção civil instaladas em Russas, os cita-se o escritório denominado Odilo Almeida Arquitetura e Urbanismo. É um escritório especializado na elaboração de projetos residenciais e de execução de obras, com sede em Fortaleza e foi fundado no ano de 1994. Os principais campos de atuação do escritório são: arquitetura residencial, comercial e de serviços; projetos urbanísticos; arquitetura de interiores; elaboração e revisão de planos diretores, arquitetura paisagística, incorporação e venda de imóveis e inspeção predial. Nos empreendimentos construídos em Russas, o arquiteto responsável é originário da cidade e possui vários projetos não apenas em Russas, mas em outras regiôes do estado. $\mathrm{O}$ empreendimento localiza-se no bairro Tabuleiro do Catavento e é composto por casas com sala, cozinha americana, quintal, dois quartos, banheiro, garagem e varanda (figuras 6 e 7 ).

Figuras 6 e 7 - Empreendimento no Bairro Tabuleiro do Catavento

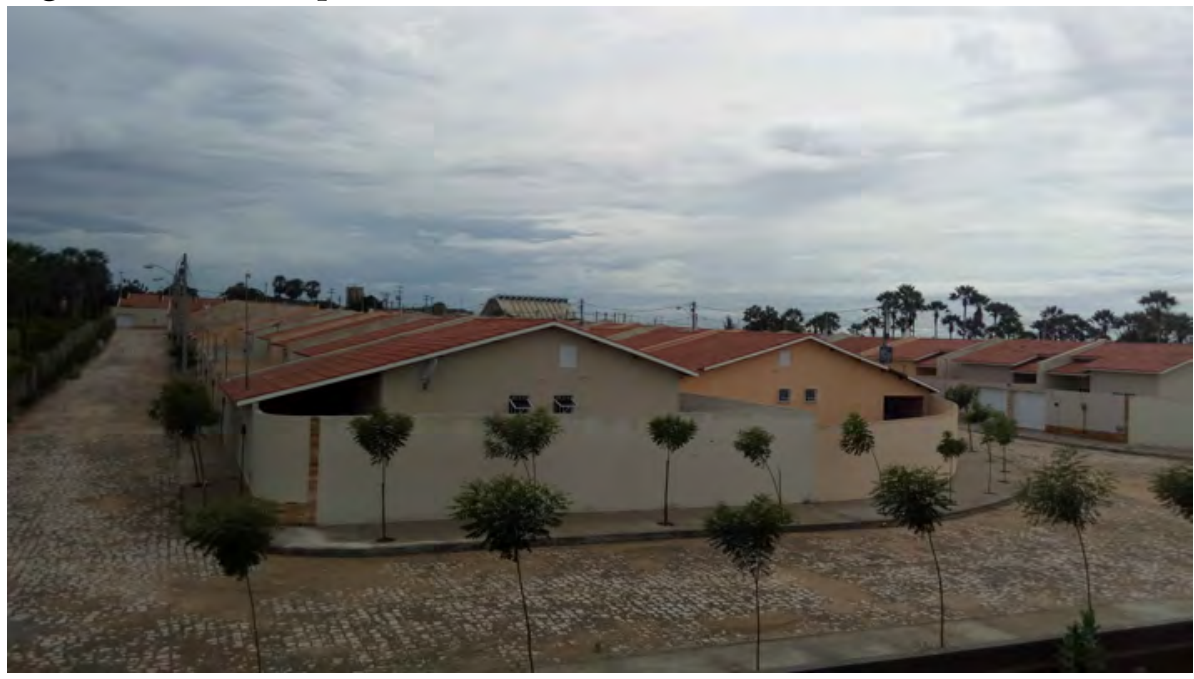




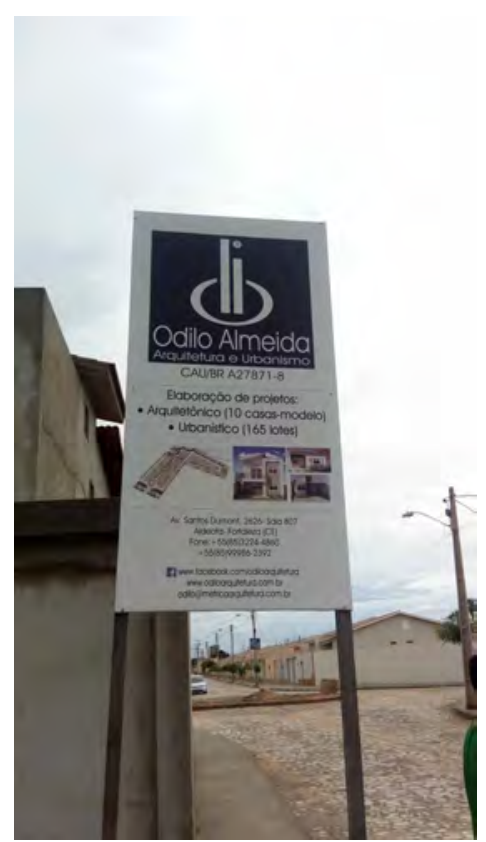

Foto: Sousa, 2018. Trabalho de Campo.

Ao compararmos as primeiras unidades construídas no âmbito do PMCMV com os empreendimentos mais recentes, observamos que houve uma mudança significativa na estrutura, no tamanho, na aparência, na localização e nos valores destes imóveis. Na observação in loco foi possível apreender que existem perceptíveis diferenciaçôes na estrutura dos imóveis do programa. Inicialmente, tais diferenças se dão pelas alteraçóes sofridas pelo programa nas suas diferentes versôes. Na versão de 2017, algumas normativas foram acrescidas, destacando-se a obrigatoriedade de todas as unidades terem aquecimento de água por energia solar e serem adequadas à acessibilidade (rampas, banheiros adaptados etc.). Além disso, vale acrescentar que muito embora se trate de um programa nacional e que as normativas sejam válidas para todo o território, o que implica em vários problemas pela diversidade - regional, climática, costumes etc. -, além das diferenças das faixas por renda familiar, constata-se diferenças nos padróes de estrutura construtiva. Em Russas, isso é evidente. Significa afirmar que os conjuntos nas faixas $2 \mathrm{e}$ 3 existentes na cidade apresentam diferenciaçôes nítidas comparadas com os 
empreendimentos das mesmas tipologias construídos nas cidades de Fortaleza ou São Paulo, por exemplo.

Apesar dessa diferença, alguns elementos vêm se mantendo ao longo dos anos e são comuns a outras cidades e regiōes. É o caso, por exemplo, dos empreendimentos construídos em áreas periféricas não dotadas de infraestrutura e de serviços públicos. Essas áreas são escolhidas pelos construtores por terem um menor preço no mercado imobiliário, potencializando as possibilidades de maior rentabilidade.

De maneira geral, observamos que a maioria dos empreendimentos está localizada em áreas e bairros periféricos e que nenhuma unidade foi construída nas áreas contíguas ao centro da cidade, já que se trata de um núcleo cuja dinâmica urbana é centralizada e a malha não é por demais extensa, além de apresentar terrenos ociosos. O mapa 2 mostra a espacialização dos empreendimentos existentes na cidade de Russas e as faixas de renda em que são classificadas. Com base neste mapa, verificamos que a maior parte dos empreendimentos se estende para as áreas periféricas da cidade. De acordo com a espacialização indicada, é possível observar que os empreendimentos estáo distribuídos entre seis dos 13 bairros que compóem o espaço urbano de Russas, e um localizado fora dos limites do perímetro urbano, o primeiro construído por meio do PMCMV na cidade, ainda em 2009. A maior concentração desses empreendimentos ocorre no bairro Tabuleiro do Catavento, onde há a predominância de conjuntos formados por dezenas de casas e que vêm modificando a paisagem e a dinâmica do referido bairro. 
Mapa 2 - Localização dos empreendimentos do PMCMV em Russas

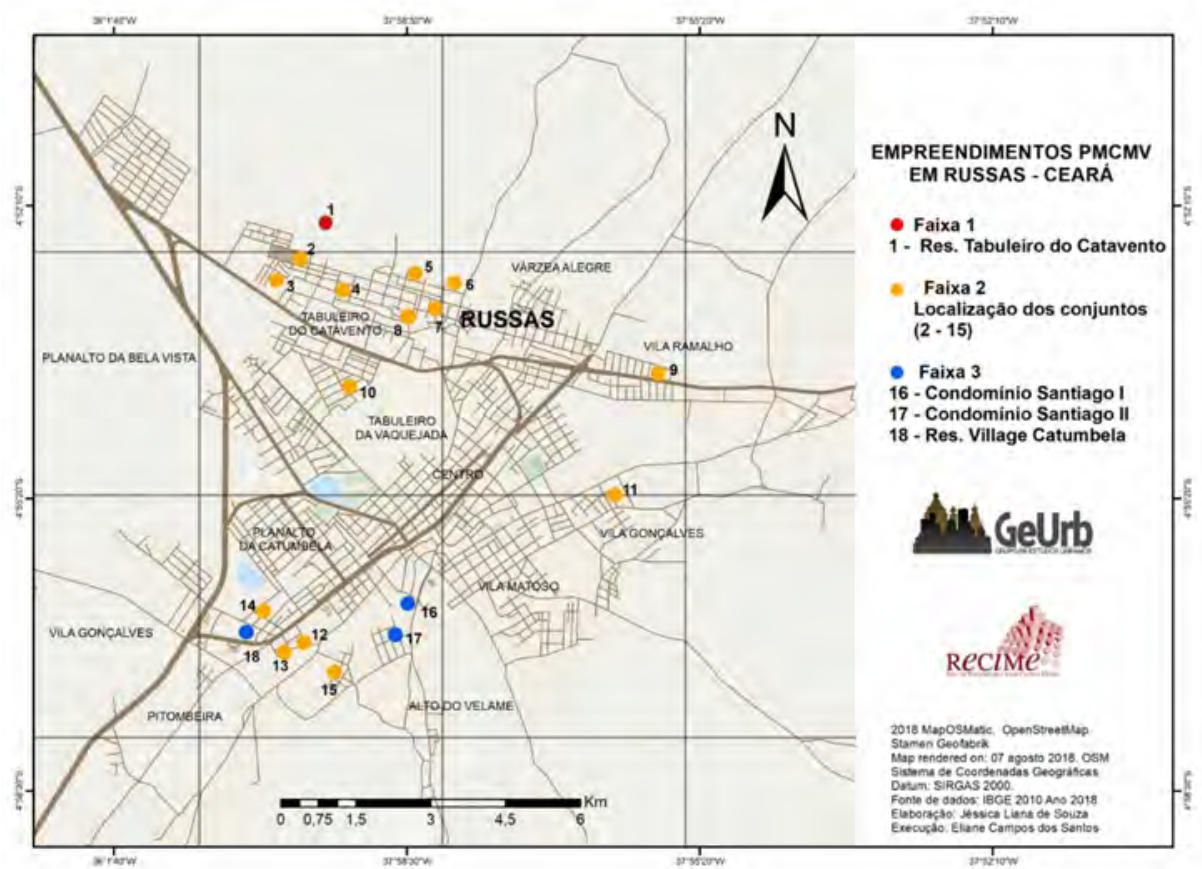

Fonte: IBGE 2010. Ano 2018.

Os bairros Nossa Senhora de Fátima e Planalto da Catumbela também apresentam quantidade significativa de empreendimentos. O bairro Nossa Senhora de Fátima, que desde 2010 vem recebendo a construção dessas unidades, possui uma quantidade de UHs bem superior ao bairro Planalto da Catumbela, onde a construção dessas unidades é mais recente.

Podemos observar que os empreendimentos estão, em sua maioria, localizados em áreas adjacentes ao centro da cidade, intermediadas por grandes vazios, e de menor ocupação. Dessa forma, o PMCMV, ao passo que potencializou e expandiu o mercado imobiliário na cidade, ativa o processo de segregação em Russas. Nesse sentido, essa distribuição locacional é uma estratégia do mercado imobiliário para garantir maior rentabilidade dos seus negócios.

Recentemente usando o PMCMV como objeto de análise, Cardoso e Aragão (2013) explicam essa estratégia afirmando que os lucros adquiridos pelas construtoras não se limitam aos conseguidos por meio do processo de construção, mas também inclui o lucro que pode ser retirado no processo de mercantilização das unidades. 
Essa estratégia de "maximização de lucros" está integralmente ligada à transformação do solo, uma vez que os preços são pensados pelas características definidas pelo setor imobiliário como atributos de valorização, que variam da localização dos empreendimentos até a estrutura oferecida em seu entorno. Tal prática é também observada em Russas. Os empreendimentos do PMCMV estão localizados em áreas periféricas e com distância considerável do centro da cidade, onde se concentra a grande maioria dos serviços públicos e privados como hospitais, escolas, e empreendimentos comerciais.

O bairro Tabuleiro do Catavento é o maior expoente dessa estratégia. Este bairro tem sido historicamente um dos vetores de direcionamento das famílias de baixo poder aquisitivo, inclusive por meio da construção de dois conjuntos habitacionais, e sempre apresentou uma carência de infraestrutura e de serviços urbanos, o que acarreta numa desvalorização dos terrenos localizados em seus limites.

Apesar de não ter sido contemplado por projetos de infraestrutura que atendam às demandas e que estimulem a sua ocupação, nesse bairro estão sendo construídos empreendimentos financiados pelo PMCMV desde 2010 e hoje é o que abraça a maior quantidade de unidades comercializadas pelo programa em Russas.

No bairro Nossa Senhora de Fátima também estão sendo construídas muitas unidades por meio do PMCMV, localizadas em terrenos não loteados, adquiridos exclusivamente para a construção dos empreendimentos e que também não oferecem pavimentação.

Já os empreendimentos situados no bairro Planalto da Catumbela encontram-se próximos a áreas já consolidadas, bastante habitadas e dotadas de infraestrutura como pavimentação e saneamento básico. A maioria das unidades construídas no bairro Ipiranga também possuem vias pavimentadas.

As mudanças na variedade, padrão e qualidade dos empreendimentos lançados recentemente em Russas resultam da modernização e especialização do setor imobiliário na cidade e que, no nosso entender, sofre influência dos incentivos oportunizados pelo PMCMV. Afirmamos tal compreensão com base nas mudanças que ocorreram neste setor a partir da intervençáo gerada pelo programa, principalmente depois de 2010, e que são perceptíveis na cidade.

Além disso, é possível dizer que foi a partir dos incentivos do PMCMV que a construção empresarial de moradias começou a ocorrer de 
forma expressiva na cidade. Ou seja, a institucionalização deste programa na cidade de Russas possibilitou o surgimento de empresas e construtoras vinculadas ao mercado imobiliário pelos próprios empresários que residem e moram em Russas, bem como de outras cidades, em sua maioria de Fortaleza e, como já foi mencionado, de Minas Gerais (LCM Construção), responsável pelos empreendimentos da faixa 1 que seráo construídos em etapas posteriores.

Pela espacialização dos empreendimentos mostrada anteriormente no mapa 2 e apresentada no próprio texto, podemos observar que bairros periféricos, antes habitados apenas por famílias de baixa renda estâo recebendo empreendimentos do PMCMV. Como vimos, essa localização faz parte da estratégia de maximização dos lucros das construtoras. No entanto, é preciso destacar que esses empreendimentos tendem a gerar mudanças nas dinâmicas socioespaciais dos bairros onde se localizam. As novas famílias que passam a residir nesses bairros geram de imediato um novo fluxo de pessoas e veículos por suas vias e tendem, com o passar dos anos, a atrair a instalaçáo de novos comércios e serviços, como mercadinhos e lanchonetes.

A construçáo de um conjunto residencial e a consecutiva dotaçáo de infraestrutura valorizam os terrenos no entorno, estimulando os proprietários a uma espera especulativa. Produzem-se novos vazios urbanos, ao passo que a população que precisa de habitação, mas não pode pagar pelo seu preço nas áreas mais equipadas, precisa deslocar-se para mais longe, ampliando o processo de periferização.

Neste sentido, podemos observar que o PMCMV tem impulsionado o surgimento e a atuação de novas empresas no ramo da construção civil em Russas e estas, por meio da compra de terras menos valorizadas, têm gerado a ocupação e a diversificação da habitação de áreas periféricas da cidade, principalmente nos bairros Tabuleiro do Catavento e Nossa Senhora de Fátima.

Além dessas consideraçóes, a oferta de outros serviços públicos como o saneamento básico, a iluminação pública e a coleta de lixo nessas unidades, ou seja, a dotaçáo dos equipamentos de consumo coletivo pelo Estado, bem como a localizaçáo dos empreendimentos em relaçáo aos espaços de lazer, entretenimento, alimentação e comércio, por exemplo, também precisam ser analisadas para termos uma melhor leitura sobre as condiçóes de inserção urbana desses empreendimentos. 


\section{Consideraçóes finais}

Discutimos alguns dos processos socioespaciais decorrentes da implementação do PMCMV na produção do espaço urbano e na expansão da cidade supracitada. Os números da produção habitacional por meio do PMCMV em Russas apresentados são significativos, principalmente por se tratar de uma pequena cidade que não apresentava um histórico de construção de moradias na forma empresarial. Este, certamente, foi o ponto de partida para encontrarmos os efeitos do programa em Russas. Compreendemos que a atuação do setor empresarial no ramo da construção civil em Russas se desenvolve a partir do crescimento do acesso ao crédito imobiliário oferecido pelo PMCMV. A atuação do Estado por meio deste programa tem fomentado o desenvolvimento do setor imobiliário.

Como se pôde observar por meio da espacialização e das demais características dos empreendimentos comercializados em Russas, o setor empresarial tem optado por construir a maioria dos empreendimentos em áreas mais afastadas do centro da cidade, onde as terras possuem preços mais baixos e garantem um lucro maior no final do processo construtivo. Dentro desta estratégia podemos destacar principalmente os Bairros Tabuleiro do Catavento e Nossa Senhora de Fátima.

Além disso, a demanda por moradia e a crescente procura pelas condições oferecidas pelo PMCMV (subsídios e financiamentos com baixos juros) têm gerado o surgimento de empresas especializadas na construção civil, especificamente para fins de financiamento mediante o programa. Tal realidade foi bem explorada e trabalhada por Araújo (2017) ao estudar as cidades de Patos e Cajazeiras na Paraíba. Em Russas, apesar de existir a atuação de empresas de outras cidades, como Fortaleza, Aracati e Mossoró, a predominância no setor é de empresas locais, algumas fundadas há menos de seis anos. Surgem novos agentes entre os produtores do espaço urbano. Novos construtores, novos corretores, novas terras a serem comercializadas, algumas agora valorizadas pela ótica imobiliária apenas pela sua aproximação com os empreendimentos do PMCMV. Com elas, surgem também novos proprietários fundiários do espaço urbano.

Nesse momento, a cidade de Russas vem passando por um rápido processo de expansão da malha urbana e por um forte incremento do mercado imobiliário local. Com mais possibilidades de acesso à casa própria também 
por parte das famílias de renda média e, mais recentemente, principalmente por esta faixa, ativa-se o setor construtivo e o mercado imobiliário. Assim, o espraiamento da cidade vai ocorrendo de forma acelerada e em descompasso com a oferta de infraestrutura.

A pesquisa mostra também que a localização dos empreendimentos construídos pode trazer ônus aos seus compradores dada à precária ou mesmo ausente inserção urbana e o distanciamento das áreas centrais. A predominância dos empreendimentos para as faixas 2 e 3 do programa reafirma o caráter econômico e empresarial da política pública de provisão habitacional para famílias de baixo poder aquisitivo. A não priorização ao acesso à moradia para a faixa da populaçáo que efetivamente carece em Russas foi constatada desde o início da pesquisa, ao se verificar a inexistência de habitaçóes da faixa 1 do PMCMV.

Portanto, constatamos que o PMCMV tem propiciado o surgimento de novas dinâmicas no setor imobiliário de Russas, com novos agentes, meios de construção e áreas de atuação, e com ela, a produção e expansão do espaço urbano tem adquirido novas formas, mantendo a segregação ao acesso à habitação e à cidade. Observa-se cada vez mais, a consolidação de duas periferias bem distintas: a dos conjuntos habitacionais, onde habita, predominantemente, a população de baixa renda, e a dos pequenos condomínios fechados e grandes loteamentos direcionados para a população de renda mais elevada. Esses espaços se diferenciam, principalmente, por sua morfologia e conteúdo social.

\section{Referências}

ARAÚJO, Luciana Medeiros. de. Produção Imobiliária e novas Dinâmicas de Expansão Urbana em Patos e Cajazeiras (PB). (Tese). João Pessoa - PB: Universidade Federal da Paraíba, 2017. CORRÊA, Roberto Lobato. O espaço urbano. 4. ed. São Paulo, Ática, 2002.

CARLOS, Ana Fani Alessandri et al. (org.). A produção do espaço urbano: agentes e processos, escalas e desafios. 1a. ed. São Paulo: Contexto, 2011.

HENRIQUE, Wendel. "Cidades universitárias, cidades médias, cidades pequenas: análises sobre o processo de instalação de novos Campi universitário". In: Revista Espaço Aberto, $P P G G$ - UFRJ, v. 5, n. 1, pp. 73-93, 2015.

LEFEBVRE, Henry. “O Espaço”. In: Espaço e política. Belo Horizonte: UFMG, 2008. 
PEQUENO, Renato e FREITAS, Clarissa. "Programa minha Casa minha Vida em Fortaleza: primeiros resultados". In: CARDOSO, Adauto Lucio. O programa Minha Casa Minha Vida e seus efeitos territoriais. Rio de Janeiro: Letra Capital, 2013.

SANTOS, Milton. A urbanização brasileira. São Paulo, Hucitec, 1993.

VALENÇA, Mariana Rabêlo. Ensino Superior e Empreendimentos Imobiliários do Programa Minha Casa Minha Vida: uma análise sobre as interaçôes espaciais de Caruaru - PE. (Tese). João Pessoa - PB: Universidade Federal da Paraíba, 2018.

VOLOCHKO, Danilo. A produção do espaço e as estratégias reprodutivas do capital: negócios imobiliários e financeiros em São Paulo. (Dissertação). São Paulo: Universidade de São Paulo, 2007. 